\title{
Eco-Bat: A Design Tool for Assessing Environmental Impacts of Buildings and Equipment
}

\author{
Didier Favre( $\square)$, Stéphane Citherlet \\ Laboratory of Solar Energetics and Building Physics, University of Applied Sciences of Western Switzerland, \\ CH-1401 Yverdon-Les-Bains, Switzerland
}

Received: 21 November 2007 / Revised: 14 January 2008 / Accepted: 15 January 2008

C Tsinghua Press and Springer-Verlag 2008

\begin{abstract}
This paper presents the features of Eco-Bat, a computer program developed to assess the environmental impacts of buildings, including construction materials and energy consumed, during its life cycle. The methodology used to evaluate environmental impacts based on a life cycle assessment (LCA) approach, compatible with ISO 14040 standards, is detailed. The data are mainly extracted from an environmental impacts database, Ecoinvent, which contains values for the manufacturing and elimination of numerous materials as well as other processes. Two applications are presented to illustrate the possibilities offered by Eco-Bat. The first one is a comparison of different variants of building facades. The second example shows the analysis of a whole building including its energy consumption.
\end{abstract}

Keywords environmental impacts, life cycle impacts assessment, ecobalance

\section{Introduction}

For low-energy buildings, the environmental impacts due to energy consumption are of the same order of magnitude as the impacts generated by the construction materials during the building life span. Therefore, the reduction of environmental impacts on low-energy buildings should not only focus on the reduction of its energy consumption but also on the use of environmental-friendly construction materials.

Unfortunately, the calculation of these impacts is a long and painful exercise. Therefore, it is important for planners, architects and engineers, as well as students, to have access to a user-friendly tool that can perform a detailed assessment of the environmental impacts of buildings.

A new computer program, named Eco-Bat, has been developed at the Laboratory of Solar Energetics and Building Physics at the University of Applied Sciences of Western Switzerland. Eco-Bat allows evaluating the environmental

E-mail: info@eco-bat.ch impacts generated by a building or part of it during its life cycle. It is currently used by architects and engineers in Switzerland, Italy, and France to evaluate impacts of family houses, rental buildings, offices, and schools. Eco-Bat is also used in a project which intends to build an ecological district in a Swiss city.

\section{Environmental impacts}

\subsection{Building life cycle}

The environmental impacts of a building depend on two major contributions:

- The construction materials

- The energy consumption (use phase)

Figure 1 shows the different phases occurring during a building's life cycle. Each stage of the building life cycle represented on Fig. 1 has a negative effect on the environment. The construction phase consists of raw material extraction and their transformation into finished products that can be used on the building. A large part of 
the total impacts of a material comes from the manufacturing processes. Most materials are then transported directly to the building site. Some prefabricated elements (window frames for instance) have to go through an assembly process and therefore have to be transported to a specialized facility before to be send to the building site. Environmental impacts related to the transportation can change depending on the construction site and the factories locations. Eco-Bat makes the assumption that the construction site is in Switzerland. Average distances are used for inland-found materials as well as imported ones. As the transport impacts account for a small percentage of the total impacts of a material, this approximation is adequate.

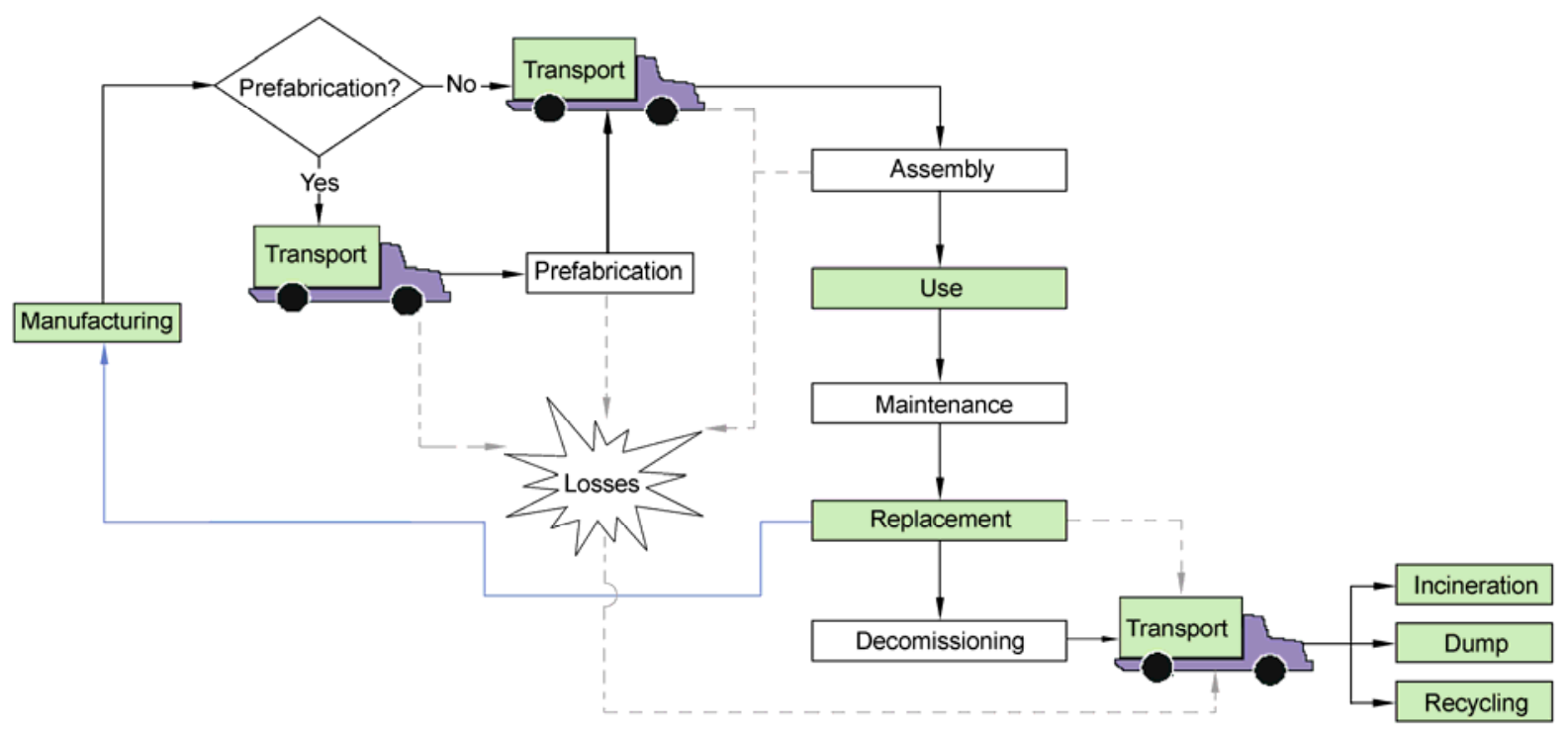

Fig. 1 Life cycle of a building

The impacts resulting from the building construction and deconstruction are not relevant when compared to the other impacts generated during the building life (Citherlet 2001). During the use phase of the building, some materials have to be replaced, as they have a shorter life span than the building. The replacement materials are also taken into account in the calculation. Their fabrication, transport, and elimination impacts have been included.

At the end of the material life, the wastes (replacement materials and building deconstruction) are transported to facilities where they will be recycled, incinerated, or buried in a landfill.

For each material, information such as life span, transport distances, vehicles used, and elimination rates is stored in the Eco-Bat database. It has been obtained through practitioners and cannot be modified by the user without special access.

The energy (heating, cooling, domestic hot water, lighting, electricity for equipments) consumed during the building occupation also generates environmental impacts. Only the heating of domestic hot water is taken into account. The impacts related to consumables, such as tap water usage or paper are not taken into account as they are less relevant than to impacts from the materials or energy consumption. For standard buildings, the environmental impacts related to the energy consumed are much higher than the impacts generated by the building materials. However, for low-energy buildings, it has been shown that the impacts of the construction materials can be similar or even higher than the impacts generated by the energy consumption (Citherlet and Defaux 2004). For such buildings, the reduction of their impacts is therefore connected to the selection of environmentally sound materials. Eco-Bat has been developed to help designers to optimise the building's environmental performances.

\subsection{Impacts indicators}

The Ecoinvent database is one of the most comprehensive source of environmental impacts data available. It regroups hundreds of materials and processes and gives impact values for many indicators. Eco-Bat uses impacts data from Ecoinvent 1.3 (EMPA). Currently, only the following four environmental indicators are implemented.

- NRE: Non-Renewable Energy, which represents the non-renewable primary energy consumed. It is an indicator of the depletion of non-renewable sources (at a human scale), such as fossil fuels. It is expressed in $[\mathrm{MJ}]$.

- GWP: Global Warming Potential, which quantifies the emission of greenhouse gases. GWP is not measured in 
an absolute unity. As each gas has a different impact on the greenhouse effect, their potential is compared to $\mathrm{CO}_{2}$. For instance, $1 \mathrm{~kg}$ of methane $\left(\mathrm{CH}_{4}\right)$ is equivalent to $23 \mathrm{~kg}$ of $\mathrm{CO}_{2}$. We can then add the contribution of each gas. Results are expressed in [ $\mathrm{kg} \mathrm{CO}_{2}$-eq].

- AP: Acidification Potential. Gas emissions that contribute to acidification. For instance, $\mathrm{SO}_{2}$ or $\mathrm{NH}_{3}$, mix with water molecules in the atmosphere to create acids. The effects can affect water, vegetation, and living species. $\mathrm{AP}$ is given in $[\mathrm{kg} \mathrm{SO}$-eq].

- POCP: Photochemical Ozone Potential. Some substances contribute to photochemical ozone production. Ozone has oxidizing properties and can lead to breathing problems or irritations on human beings. POCP is compared to ethylene and is expressed in $\left[\mathrm{kg} \mathrm{C}_{2} \mathrm{H}_{4}\right.$-eq].

There is currently not a single unique indicator that is used worldwide to evaluate environmental impacts. There are however different methods to aggregate various effects such as climate change, acidification of soils or use of resources. Each method gives more or less importance to each effect. UBP, Ecoindicator and EPS2000 are among the most famous ones. The endpoint indicators they provide are not available in the current version of Eco-Bat but they will be present in the next release.

\subsection{Calculation}

This section explains how the environmental impacts of a building element are calculated. For each phase, we have to make the sum of the impacts of the materials contained in the element.

\section{Manufacturing}

Equation (1) explains how the manufacturing impacts of an element are calculated.

$$
\overline{E I}_{j, \text { imp }}^{\text {manuf }}=\sum_{i \in j}\left(\bar{M}_{i}^{\text {manuf }} \times I F_{i, i m p}^{\text {manuf }}\right)
$$

$\overline{E I}_{j, i m p}^{\text {manuf }}$ Impact value of indicator imp generated by the manufacturing of element $j$.

$j \quad$ Building element identifier.

$i \quad$ Material identifier in element $j$.

imp Impact indicator (NRE, GWP, etc.).

$\bar{M}_{i}^{\text {manuf }} \quad$ Mass of material $i$ manufactured [kg]. Takes into account all losses occurring during transport and assembly.

$I F_{i, i m p}^{\text {manuf }} \quad$ Impact value of indicator imp generated by the manufacture of $1 \mathrm{~kg}$ of material $i$ [impact $/ \mathrm{kg}]$.

\section{Transport}

All transports impacts are calculated using Eq. (2). The weight of a material carried by two consecutive transports can be different as a small percentage of the material may be lost during previous transportation.

$\overline{E I}_{j, i m p}^{\mathrm{A}->\mathrm{B}}=\sum_{i \in j} \sum_{t}\left(\frac{\bar{M}_{i, t}^{\mathrm{A}-\mathrm{B}}}{1000} \times T D_{i, t}^{\mathrm{A}->\mathrm{B}} \times I F_{t, i m p}^{\text {Transport }}\right)$

$\overline{E I}_{j, i m p}^{\mathrm{A}->\mathrm{B}} \quad$ Impact value of indicator imp generated by the transport of element $j$ from A to B. A and B can be different location: manufacturing plant, construction site, elimination factory.

$\bar{M}_{i, t}^{\mathrm{A}->\mathrm{B}} \quad$ Mass of material $i$ transported from point A to point B by vehicle $t[\mathrm{~kg}]$.

$T D_{i, t}^{\mathrm{A}->\mathrm{B}}$ Distance travelled by vehicle $t$ while transporting material $i$ from $\mathrm{A}$ to $\mathrm{B}$.

$I F_{t, i m p}^{\text {Transport }}$ Impact of indicator imp generated by the use of vehicle $t[\mathrm{impact} /(\mathrm{t} \cdot \mathrm{km})]$.

\section{Replacement}

The replacement phase takes into account the manufacturing of the replacement materials and their transport to the building construction site. The impacts are calculated using Eq. (3).

$$
\overline{E I}_{j, \text { imp }}^{\text {Replacement }}=\sum_{i \in j}\left[N r_{i}\left(\overline{E I}_{i, i m p}^{\text {manuf }}+\overline{E I}_{i, i m p}^{\text {manuf }->\text { constr }}\right)\right]
$$

$\overline{E I}_{j, \text { imp }}^{\text {Replacement }}$ Impact value of indicator imp generated by the replacement of materials inside element $j$.

$N r_{i} \quad$ Number of times material $i$ has to be replaced during the building life span.

$\overline{E I}_{i, i m p}^{\text {manuf }}$ Impact of indicator imp generated by manufacturing material $i$.

$\overline{E I}_{i, i m p}^{\text {manuf } \rightarrow \text { constr }}$ Impact of indicator imp generated by the transport of material $i$ to the construction site.

\section{Elimination}

Each material can be eliminated by three different methods: recycling, incineration, and landfill. The elimination impacts are evaluated using Eq. (4).

$$
\overline{E I}_{j, i m p}^{\mathrm{elim}}=\sum_{i \in j} \sum_{l=1}^{3}\left(P_{i, l} \times{\overline{M_{i}}} \times I F_{i m p, l}\right)
$$

$\overline{E I}_{j, \text { imp }}^{\text {elim }}$ Impact value of indicator imp generated by the elimination of element $j$. 
$l$ Elimination type identifier. $1=$ recycling, $2=$ incineration, $3=$ landfill.

$\bar{M}_{i} \quad$ Mass of material $i$ to be eliminated [kg]. Includes the original material manufactured as well as all the replacement materials.

$P_{i, l} \quad$ Percentage of material $i$ eliminated by process $l$.

$I F_{i m p, l} \quad$ Impact imp generated by the elimination of $1 \mathrm{~kg}$ of material $i$ using process $l$ [impact $/ \mathrm{kg}]$.

\subsection{Building life span}

Each material has its own life span. Some, like concrete, will last until the building is decommissioned. Some others, like mineral wool insulation, will have to be replaced after a number of years. Eco-Bat takes the material life span into account. Therefore, the number of material replacements will depend on the building's life span. The latter can easily be changed which allows to quickly assess its effects on the results.

In order to illustrate the possibilities offered by Eco-Bat, two application examples are presented hereafter. The first one details the comparison of four variants of building facades. The second one presents the analysis of a whole building, including construction materials and energy consumed during its life cycle.

\section{Comparison of envelope elements}

This section presents the analysis of three different variants of a light-weight ventilated facade and a heavy weight element (brick). We also made the assumption that they will be integrated into a building whose life span is estimated to be 50 years.

The energy performance of a ventilated facade is not dependent on the external surface and therefore only the impacts of the construction materials have been considered in this study.

\subsection{Description of a building element}

In order to evaluate the environmental impacts of a construction element in Eco-Bat, the user has to define its composition as a multi-layer construction. This is shown on Fig. 2. First, the user has to give the area of the element. Then, for each layer of the construction element, the material used has to be selected in a list and the layer thickness has to be specified. Eco-Bat also takes into account non-uniform layer. It is possible to define the area percentage when a layer doesn't cover the whole area of the element.

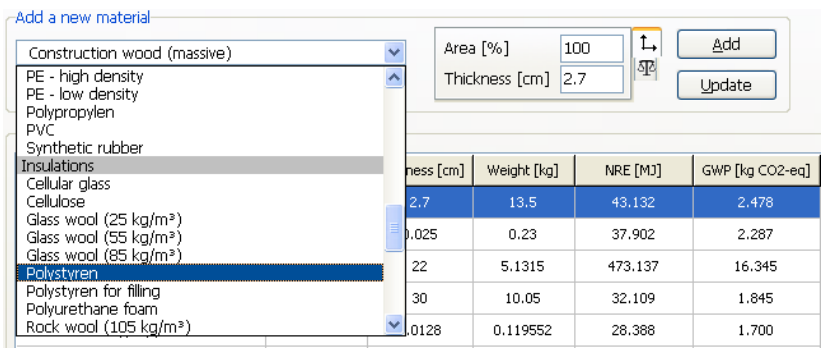

Fig. 2 Description of a building element

\subsection{Variants description}

Variant 1 is a heavy weight envelope element. It has a structure made of terra cotta bricks with external polystyrene insulation. Its composition is given in Table 1.

Table 1 Variant 1 composition

\begin{tabular}{lcc}
\hline Material & $\begin{array}{c}\text { Area } \\
\left(\mathrm{m}^{2}\right)\end{array}$ & $\begin{array}{c}\text { Thickness } \\
(\mathrm{cm})\end{array}$ \\
\hline Internal roughcast & 1.0 & 1 \\
Clay brick & 1.0 & 15 \\
Polystyrene & 1.0 & 22 \\
External roughcast & 1.0 & 2 \\
\hline
\end{tabular}

Variants 2, 3, and 4, have the same light structure, made of wood and are insulated with glass wool $\left(25 \mathrm{~kg} / \mathrm{m}^{3}\right)$ including an air-tight layer and a vapour barrier in polyethylene. The external layer is different on each variant. However, in each case it is fastened with nine stainless steel screws per $1 \mathrm{~m}^{2}$. Each screw weights $31.5 \mathrm{~g}$.

The outer surface in variant 2 is made of small wooden beams of different cross sections (average $5 \mathrm{~cm}$ ). These elements are placed horizontally and are painted with three layers of varnish on each side before assembly. We assumed that every 12 years, 2 layers are applied on the external surface during the refurbishment process. Table 2 summarises the construction materials used in variant 2 .

Table 2 Variant 2 composition

\begin{tabular}{lccc}
\hline Material & $\begin{array}{c}\text { Area } \\
\left(\mathrm{m}^{2}\right)\end{array}$ & $\begin{array}{c}\text { Thickness } \\
(\mathrm{cm})\end{array}$ & $\begin{array}{c}\text { Weight } \\
(\mathrm{kg})\end{array}$ \\
\hline Acrylic varnish & 5.83 & 0.012 & - \\
Wood (average) & 1.0 & 5 & - \\
Screws & - & - & 0.2835 \\
Rain barrier & 1.0 & 0.0128 & - \\
Glass wool & 0.933 & 22 & - \\
Massive wood & 0.067 & 30 & - \\
Vapour barrier & 1.0 & 0.025 & - \\
Wood panel & 1.0 & 2.7 & - \\
\hline
\end{tabular}


The outer layer of variant 3 is a flat panel made of fibreglass reinforced plastic with a polyester resin. The manufacturer has provided the basic data (composition, density, dimensions, etc.). A transportation distance of 600 $\mathrm{km}$ between the panel factory and the building site has been used. Table 3 gives the composition of this variant 3 .

The outer surface of variant 4 is made of the same fibreglass panel as variant 3 . But in the latter, the panel is flat, while in variant 4 the panel is corrugated and, for the same rigidity, has a lower thickness. Its composition is given in Table 4.

Table 3 Variant 3 composition

\begin{tabular}{lccc}
\hline Material & $\begin{array}{c}\text { Area } \\
\left(\mathrm{m}^{2}\right)\end{array}$ & $\begin{array}{c}\text { Thickness } \\
(\mathrm{cm})\end{array}$ & $\begin{array}{c}\text { Weight } \\
(\mathrm{kg})\end{array}$ \\
\hline Fibreglass panel & 1.0 & 0.5 & - \\
Screws & - & - & 0.2835 \\
Rain barrier & 1.0 & 0.0128 & - \\
Glass wool & 0.933 & 22 & - \\
Massive wood & 0.067 & 30 & - \\
Vapour barrier & 1.0 & 0.025 & - \\
Wood panel & 1.0 & 2.7 & - \\
\hline
\end{tabular}

Table 4 Variant 4 composition

\begin{tabular}{lccc}
\hline Material & $\begin{array}{c}\text { Area } \\
\left(\mathrm{m}^{2}\right)\end{array}$ & $\begin{array}{c}\text { Thickness } \\
(\mathrm{cm})\end{array}$ & $\begin{array}{c}\text { Weight } \\
(\mathrm{kg})\end{array}$ \\
\hline Fibreglass panel & 1.0 & 0.186 & - \\
Screws & - & - & 0.2835 \\
Rain barrier & 1.0 & 0.0128 & - \\
Glass wool & 0.933 & 22 & - \\
Massive wood & 0.067 & 30 & - \\
Vapour barrier & 1.0 & 0.025 & - \\
Wood panel & 1.0 & 2.7 & - \\
\hline
\end{tabular}

\subsection{Results}

Eco-Bat allows displaying many results. Hereafter, only some of the diagrams relevant for the analysed case study are shown. These figures are extracted from the results forms generated by Eco-Bat.

Figure 3 shows the total environmental impacts for each variant over 50 years. For all four indicators, the heavy weight variant shows the highest impacts. It can also be seen that the flat fibreglass panel (variant 3) always has higher impacts than the corrugated panel (variant 4). This result is related to the fact that the flat panel has a higher mass per unit area. Thus, for each phase of the panel life cycle (fabrication, transport, elimination), more impacts will be generated.

Figure 4 shows impacts related to each major phase of the life cycle of variant 4 . The construction phase (black area) which includes the manufacturing process is predominant. However, the GWP shows a high elimination contribution due to the incineration of the fibreglass panel. This is also the case for variant 3. Variant 1 (brick) has the highest environmental impacts. Among the materials, terra cotta bricks and roughcast have a great influence on the results, as the energy consumed to manufacture these two materials is high.

A priori, variant 2 would have been intuitively the best solution, as it is based on wood material. Despite the fact that the wood is protected by an acrylic varnish, the impacts are very close to those of the corrugated fibreglass panel. NRE, GWP, and AP impacts are slightly lower and POCP is slightly higher. Figure 5 shows the analysis of material impacts inside the wood variant. These impacts are stacked on the charts to show which proportion of the element total impacts they account for.

\begin{tabular}{|l|c|c|c|c|}
\hline \multicolumn{1}{|c|}{ Elements } & $\begin{array}{c}\text { NRE } \\
{[\text { [MJ] }}\end{array}$ & $\begin{array}{c}\text { GWP } \\
{[\mathbf{k g C O 2 - e q ]}}\end{array}$ & $\begin{array}{c}\text { AP } \\
{[\mathrm{kg} \mathrm{SOx-eq]}}\end{array}$ & $\begin{array}{c}\text { POCP } \\
{[\mathbf{k g C 2 H} \text {-eq] }}\end{array}$ \\
\hline$\square$ Variant 1 - Brick & $1 ' 721.738$ & 113.991 & 0.396 & 0.020 \\
\hline$\square$ Variant 2 - Wood & 867.898 & 43.806 & 0.184 & 0.012 \\
\hline$\square$ Variant 3 - Fiber flat & $1 ' 290.888$ & 80.380 & 0.290 & 0.015 \\
\hline$\square$ Variant 4 - Fiber undulated & 892.025 & 46.985 & 0.189 & 0.011 \\
\hline
\end{tabular}
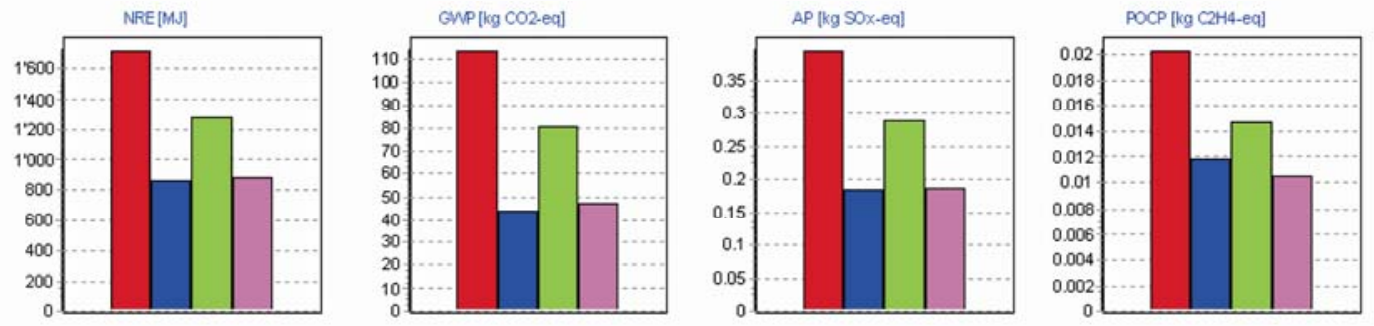

Fig. 3 Variants comparison 


\begin{tabular}{|l|c|c|c|c|}
\hline \multicolumn{1}{|c|}{ Phases } & $\begin{array}{c}\text { NRE } \\
{[\mathrm{MJ}]}\end{array}$ & $\begin{array}{c}\text { GWP } \\
{[\mathrm{kg} \mathrm{CO2-eq]}}\end{array}$ & $\begin{array}{c}\text { AP } \\
{[\mathrm{kg} \text { SOx-eq] }}\end{array}$ & $\begin{array}{c}\text { POCP } \\
{[\mathrm{kg} \text { C2H4-eq] }}\end{array}$ \\
\hline$\square$ Construction & 577.262 & 26.911 & 0.129 & 0.007 \\
\hline$\square$ Replacement & 294.553 & 10.443 & 0.053 & 0.003 \\
\hline$\square$ Elimination & 20.210 & 9.632 & 0.007 & 0.000 \\
\hline
\end{tabular}
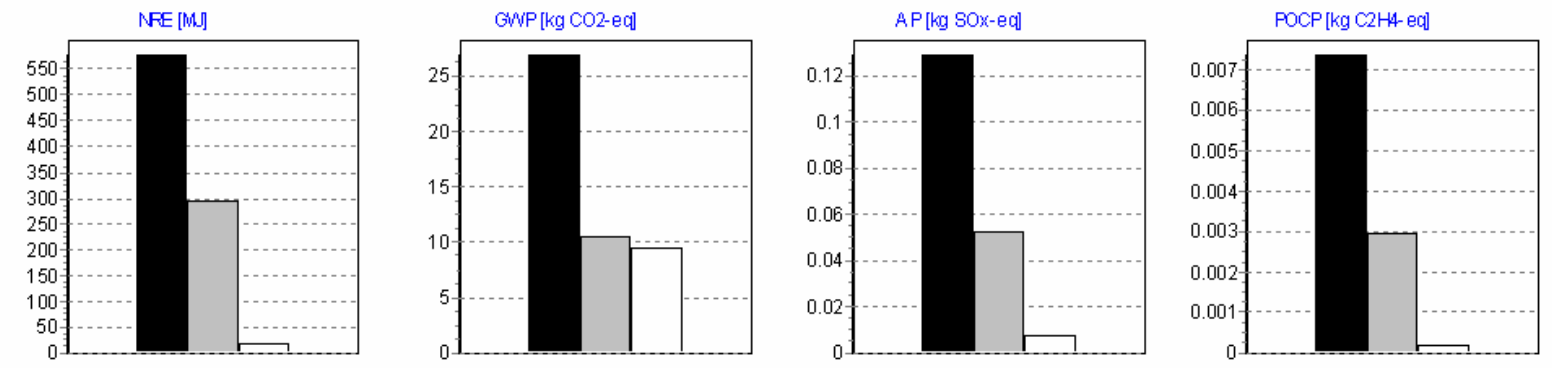

Fig. 4 Phases of the corrugated fibreglass panel variant

Some materials, such as the glass wool insulation, have a relatively high contribution as they are replaced several times during the building life span. In this example it accounts for half of the element NRE and more than a third of all other impacts. In an environmental impact assessment of construction materials, it is important to take into account the replacements. If the impacts are calculated only with the materials initially on the building, it can lead to erroneous results.
Figure 5 also shows the varnish's importance. It participates to approximately $30 \%$ of the GWP and $15 \%$ of the NRE, AP, and POCP. We could reduce the impacts by increasing the time between each refurbishment or by applying fewer layers each time. However, such measures would not guarantee the element's durability. Therefore, it would be better to use a more ecological kind of paint.

\begin{tabular}{|l|c|c|c|c|c|}
\hline \multicolumn{1}{|c|}{ Materials } & $\begin{array}{c}\text { Weight } \\
{[\mathrm{kg}]}\end{array}$ & $\begin{array}{c}\text { NRE } \\
{[\mathrm{MJ} \text {-eq] }}\end{array}$ & $\begin{array}{c}\text { GWP } \\
{[\mathrm{kg} \mathrm{CO2-eq]}}\end{array}$ & $\begin{array}{c}\text { AP } \\
{[\mathrm{kg} \mathrm{SO} 2 \text {-eq] }]}\end{array}$ & $\begin{array}{c}\text { POCP } \\
{[\mathrm{kg} \mathrm{C2H4-eq]}}\end{array}$ \\
\hline$\square$ Sawn timber (softwood) & 43.7 & 139.602 & 8.021 & 0.048 & 0.004 \\
\hline$\square$ vapour barrier PE & 0.2 & 37.902 & 2.287 & 0.007 & 0.000 \\
\hline$\square$ Glass wool (25 kg/m ${ }^{3}$ ) & 5.1 & 473.137 & 16.345 & 0.075 & 0.005 \\
\hline$\square$ Polypropylen & 0.1 & 27.621 & 1.654 & 0.008 & 0.000 \\
\hline$\square$ Acrylic varnish & 0.6 & 140.256 & 12.472 & 0.030 & 0.002 \\
\hline$\square$ Stainless steel & 0.3 & 49.380 & 3.027 & 0.017 & 0.001 \\
\hline
\end{tabular}
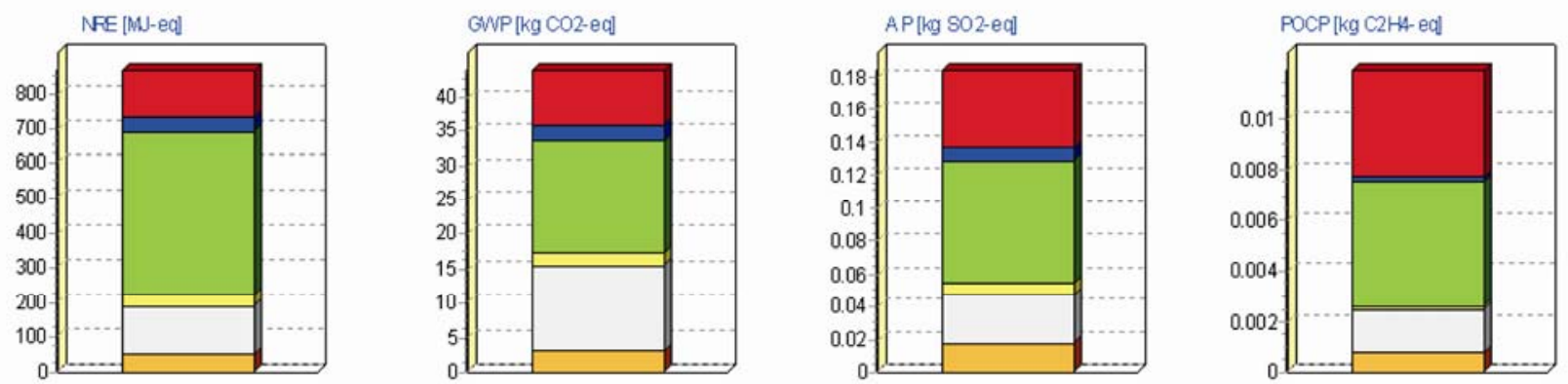

Fig. 5 Materials of the wood variant 


\section{Analysis of a building}

\subsection{Introduction}

The previous section has shown how Eco-Bat can be used to compare material variants of an element. But Eco-Bat was initially designed to analyse the environmental impacts of a whole building during its life cycle, including the construction materials and the energy consumption.

In order to achieve this goal, the user needs only to define

- the construction elements,

- the energy consumption.

The time required to define a whole building depends on its complexity. As an example, for a family house, it takes only a few minutes to create the project, assuming that all the data are known. This rapid building description process is well suited for educational and for consultancy purpose.

Figure 6 shows how a building is defined in Eco-Bat. The upper part of the window contains all the elements that user has created and at the lower part, the energy consumptions of the building are divided into the following categories:

- heating,

- cooling,

- domestic hot water,
- lighting,

- ventilation,

- electrical equipment.

For each of those consumers, the user can choose the corresponding energy vector and to give the corresponding consumption either in absolute value (MJ or $\mathrm{kW} \cdot \mathrm{h}$ ) or in relative value $\left(\mathrm{MJ} / \mathrm{m}^{2}\right.$ or $\left.\mathrm{kW} \cdot \mathrm{h} / \mathrm{m}^{2}\right)$. In the latter case, the building heated floor area has to be set.

Eco-Bat provides electricity data for all European countries, which include local production mix with electricity importation. It also provides the electricity data for the UCTE-mix (average of European countries). There are many energy production systems available, such as

- fossil fuels (various oil and gas system),

- heat pumps (various),

- $\quad$ wood (logs and pellets),

- solar thermal and Solar photovoltaic.

\subsection{Building description}

The building analysed in this study is a seven levels rental property called "La Tambourine", located in Carouge (Switzerland), with a heated floor area of $4460 \mathrm{~m}^{2}$. The south-west facade of the building is shown in Fig. 7.

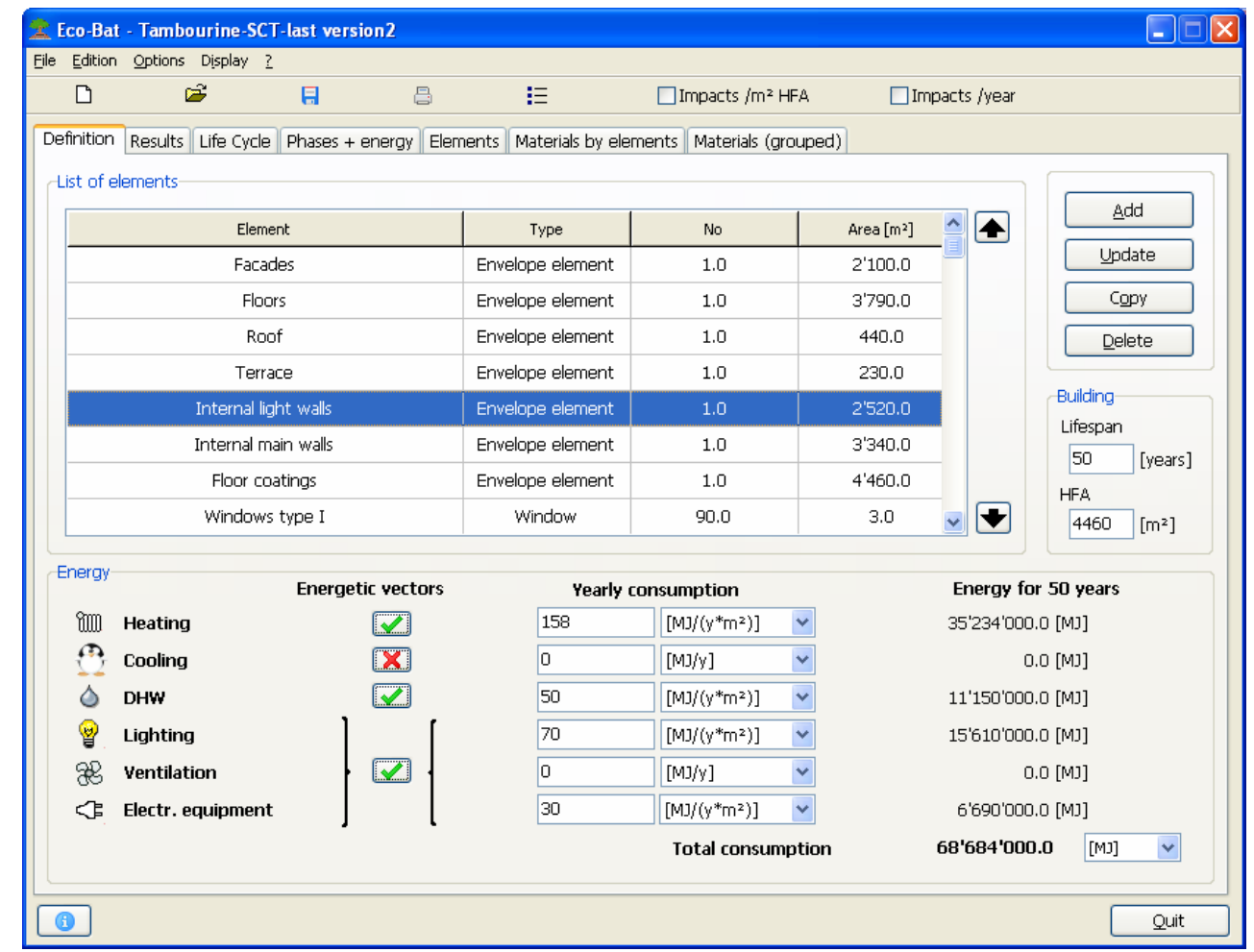

Fig. 6 Analysis of a building

${ }^{1}$ La Tambourine L6, 31 - 33 rue de la Tambourine, 1227 Carouge. This building has been designed by Bureau d'Architectes et d'Ingénieurs B. Schlunegger, Route de Collex 12, 1294, Genthod. 


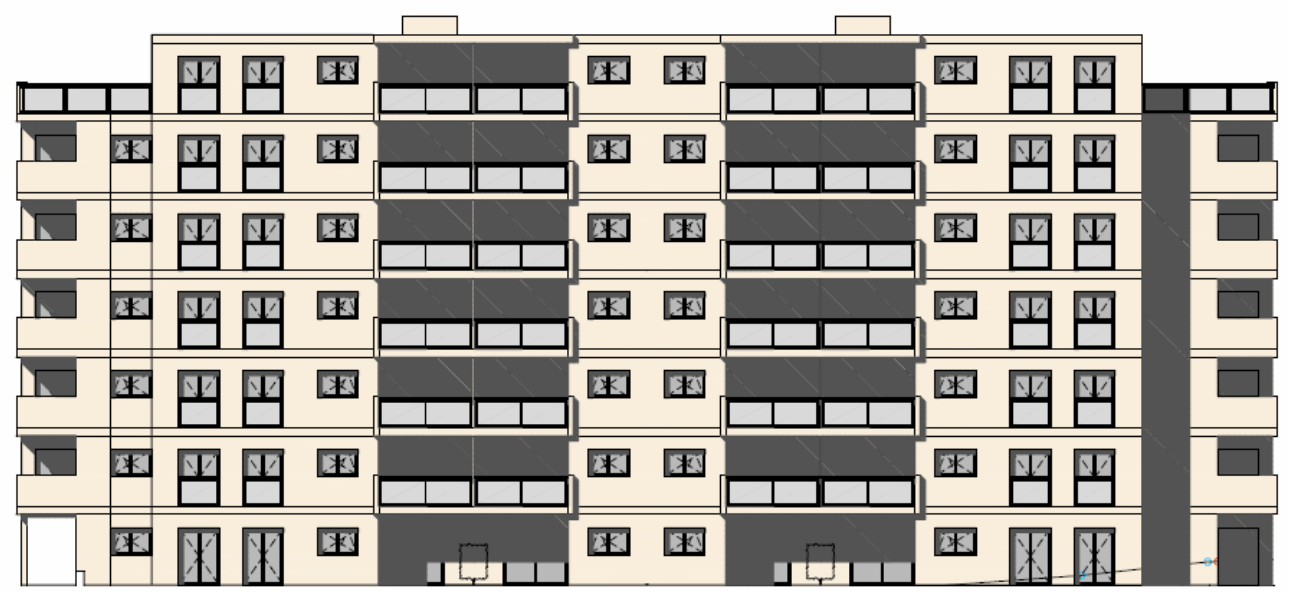

Fig. 7 South-west facade (source: Bureau d'Architectes et d'Ingénieurs B. Schlunegger)

The environmental impacts in this study have been calculated for a building lifespan of 50 years.

The folowing tables shows the composition of the different building element.

\section{Facades}

The envelope is made of concrete and terra cotta bricks with glass wool insulation.

\begin{tabular}{|c|c|c|c|}
\hline Material & Area $\left[\mathrm{m}^{2}\right]$ & Thickness $[\mathrm{cm}]$ & Weight $[\mathrm{kg}]$ \\
\hline Mineral cover coat & 2215 & 2 & 66450 \\
\hline Reinforced concrete for walls & 2215 & 15 & 942261 \\
\hline Glass wool $\left(85 \mathrm{~kg} / \mathrm{m}^{2}\right)$ & 2215 & 8 & 15062 \\
\hline Terra cotta bricks & 2215 & 4 & 97460 \\
\hline Mineral cover coat & 2215 & 1 & 33225 \\
\hline Acrylic dispersion & 2215 & 0.01 & 138.659 \\
\hline
\end{tabular}

\section{First Floor}

\begin{tabular}{|c|c|c|c|}
\hline Material & Area $\left[\mathrm{m}^{2}\right]$ & Thickness $[\mathrm{cm}]$ & Weight $[\mathrm{kg}]$ \\
\hline Reinforced concrete for slab & 540 & 20 & 288576 \\
\hline Polystyren expandable (EPS) & 540 & 4 & 388.8 \\
\hline Cement cast plaster floor & 540 & 7 & 83160 \\
\hline Polyurethane foam & 540 & 6 & 1620 \\
\hline Mineral cover coat & 540 & 1 & 8100 \\
\hline
\end{tabular}

\section{Floors}

\begin{tabular}{|c|c|c|c|}
\hline Material & Area $\left[\mathrm{m}^{2}\right]$ & Thickness $[\mathrm{cm}]$ & Weight $[\mathrm{kg}]$ \\
\hline Cement cast plaster floor & 3790 & 8 & 667040 \\
\hline Polystyren expandable (EPS) & 3790 & 4 & 2728.8 \\
\hline Reinforced concrete for slab & 3790 & 20 & 2025376 \\
\hline Mineral cover coat & 3790 & 1 & 56850 \\
\hline Acrylic dispersion & 3790 & 0.01 & 237.254 \\
\hline
\end{tabular}

Terrace and roof

The last floor of the building is made of a $230 \mathrm{~m}^{2}$ terrace and a $440 \mathrm{~m}^{2}$ indoor inhabited area.

\begin{tabular}{|c|c|c|c|}
\hline Material & Area $\left[\mathrm{m}^{2}\right]$ & Thickness $[\mathrm{cm}]$ & Weight [kg] \\
\hline Concrete (non-reinforced) & 230.0 & 7.0 & 38269.7 \\
\hline Rock wool (105 kg/m²) & 230.0 & 10.0 & 2415.0 \\
\hline Waterproofing (Polymerbitume) & 230.0 & 1.0 & 2760.0 \\
\hline Reinforced concrete for slab & 230.0 & 20.0 & 122912.0 \\
\hline Mineral cover coat & 230.0 & 1.0 & 3450.0 \\
\hline Acrylic dispersion & 230.0 & 0.01 & 14.398 \\
\hline Material & Area $\left[\mathrm{m}^{2}\right]$ & Thickness $[\mathrm{cm}]$ & Weight [kg] \\
\hline Waterproofing (Polymerbitume) & 440.0 & 1.0 & 5280.0 \\
\hline Rock wool $\left(105 \mathrm{~kg} / \mathrm{m}^{3}\right)$ & 440.0 & 10.0 & 4620.0 \\
\hline Reinforced concrete for slab & 440.0 & 20.0 & 235136.0 \\
\hline Mineral cover coat & 440.0 & 1.0 & 6600.0 \\
\hline Acrylic dispersion & 440.0 & 0.01 & 27.544 \\
\hline
\end{tabular}

Internal light walls

The internal bulkheads are made of terra cotta brick with mineral roughcast on both sides.

\begin{tabular}{|c|c|c|c|}
\hline Material & Area $\left[\mathrm{m}^{2}\right]$ & Thickness $[\mathrm{cm}]$ & Weight $[\mathrm{kg}]$ \\
\hline Acrylic varnish & 2520 & 0.01 & 231.84 \\
\hline Mineral cover coat & 2520 & 1 & 37800 \\
\hline Terra cotta bricks & 2520 & 6 & 166320 \\
\hline Mineral cover coat & 2520 & 1 & 37800 \\
\hline Acrylic varnish & 2520 & 0.01 & 231.84 \\
\hline
\end{tabular}

Internal main walls

The main internal walls are made of $18 \mathrm{~cm}$ of reinforced concrete with mineral roughcast on both sides. 


\begin{tabular}{|c|c|c|c|}
\hline Material & Area $\left[\mathrm{m}^{2}\right]$ & Thickness $[\mathrm{cm}]$ & Weight $[\mathrm{kg}]$ \\
\hline Acrylic dispersion & 3340 & 0.01 & 209.084 \\
\hline Mineral cover coat & 3340 & 1 & 50100 \\
\hline Reinforced concrete for walls & 3340 & 18 & 1705003.2 \\
\hline Mineral cover coat & 3340 & 1 & 50100 \\
\hline Acrylic dispersion & 3340 & 0.01 & 209.084 \\
\hline
\end{tabular}

\section{Floor coatings}

Half of the heated floor area of the building is covered with a wooden floor. Kitchen and bathrooms is made of ceramic tiles ( $20 \%$ of the area) while polyamide carpet is used in some other rooms ( $30 \%)$.

\begin{tabular}{|c|c|c|c|}
\hline Material & Area $\left[\mathrm{m}^{2}\right]$ & Thickness $[\mathrm{cm}]$ & Weight $[\mathrm{kg}]$ \\
\hline Ceramic tiling & 892 & 1 & 16948 \\
\hline Carpet (polyamide) & 1338 & 1 & 2676 \\
\hline Sawn timber (hardwood) & 2230 & 1 & 14495 \\
\hline Acrylic varnish & 2230 & 0.02 & 410.32 \\
\hline
\end{tabular}

\section{Windows}

There are four different kind of windows in this building. They are all double glazing windows and use the materials shown in the following table. Their only difference is the perimeter of the frame and the glazing area.

\begin{tabular}{|c|c|}
\hline Material & Thickness $[\mathrm{cm}]$ \\
\hline Argon & 1.2 \\
\hline PVC frame & - \\
\hline Aluminium spacer & - \\
\hline Coated glass & 0.4 \\
\hline Clear float glass & 0.4 \\
\hline
\end{tabular}

Sink and toilets

The flexibility of Eco-Bat also allows the user to add any other object in his project. Eco-Bat has already been used to evaluate impacts of installations such as solar adsorptive refrigerators (Hildbrand and Citherlet 2007). In this study, sinks or bath tubes has been defined by selecting the corresponding material type and by giving the material mass.

\section{Energy consumption}

Figure 8 shows the energy consumption of the building. Natural gas is used for heating. Domestic hot water uses a solar flat plate collector coupled with gas. All the electricity comes from the Swiss low voltage grid in this example, but Eco-Bat provides a list of electricity at grid for various countries.

\subsection{Results}

Figure 9 shows the impacts related to the materials and to the energy consumption for the different indicators. Comparing the relative contribution of the construction materials vs. the energy consumption, allows determining where the effort must be put to reduce the environmental impacts of a building. It has been shown (Citherlet and Defaux 2007) that for low energy building, construction materials can have higher environmental impacts than the energy consumed, depending on the energy vector used (oil, wood pellets, etc.), energy consumption, and the building location. This latest has an influence on the environmental impacts of the electricity.

We can see that for the AP and the POCP indicators, the materials impacts account for a little more than half of the building total impacts. That is not the case for the two other indicators. The GWP of the energy consumption is twice as high as the GWP of the materials. For the NRE indicator, the energy consumption account to $80 \%$ of the total impacts. This is related to the fact that heating uses fossil resources (gas) and the Swiss electricity mix uses around $50 \%$ of non-renewable energy. As this case study is not a low-energy building, to reduce the impacts of the building, the primary target would be to reduce the energy consumption for heating and lighting.

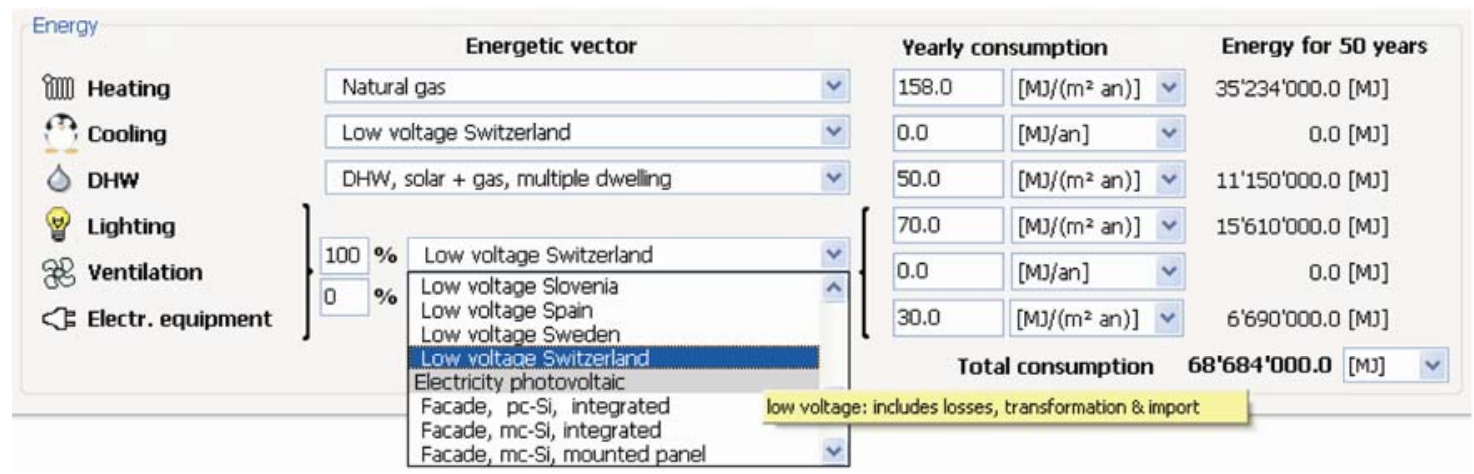

Fig. 8 Building energy consumption 


\begin{tabular}{|c|c|c|c|c|}
\hline Phases & $\begin{array}{l}\text { NRE } \\
{[\mathrm{MJ}]}\end{array}$ & $\begin{array}{c}\text { GWP } \\
\text { [kg CO2-eq] }\end{array}$ & $\begin{array}{c}A P \\
\text { [kg SOx-eq] }\end{array}$ & 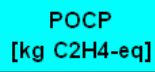 \\
\hline Construction & $20^{\prime} 828^{\prime} 626.5$ & $1^{\prime} 620^{\prime} 490.6$ & $5^{\prime} 782.0$ & 473.2 \\
\hline$\square$ Replacement & $4^{\prime} 832^{\prime} 106.0$ & $228^{\prime} 826.4$ & $1^{\prime} 098.2$ & 58.1 \\
\hline$\square$ Elimination & $2^{\prime} 9711^{\prime} 258.5$ & $236^{\prime} 858.6$ & 973.2 & 28.9 \\
\hline$\square$ Heating & $44^{\prime} 663^{\prime} 886.8$ & $2^{\prime} 607 ' 386.5$ & $2^{\prime} 636.8$ & 314.8 \\
\hline$\square \mathrm{DHW}$ & $11^{\prime} 530^{\prime} 237.3$ & $675^{\prime} 310.9$ & 631.3 & 76.0 \\
\hline$\square$ Lighting & $35^{\prime} 729^{\prime} 989.2$ & $619^{\prime} 023.2$ & $2^{\prime} 004.9$ & 63.4 \\
\hline$\square$ Electr. equipment & $15^{\prime} 312^{\prime} 852.5$ & $265^{\prime} 295.7$ & 859.3 & 27.2 \\
\hline$\square$ Total MATERIALS Impacts & $28^{\prime} 631^{\prime} 991.1$ & $2^{\prime} 086^{\prime} 175.6$ & $7 ' 853.4$ & 560.2 \\
\hline$\square$ Total ENERGY impacts & $107^{\prime} 236^{\prime} 966.0$ & $4^{\prime} 167^{\prime} 016.3$ & $6^{\prime} 132.3$ & 481.4 \\
\hline
\end{tabular}
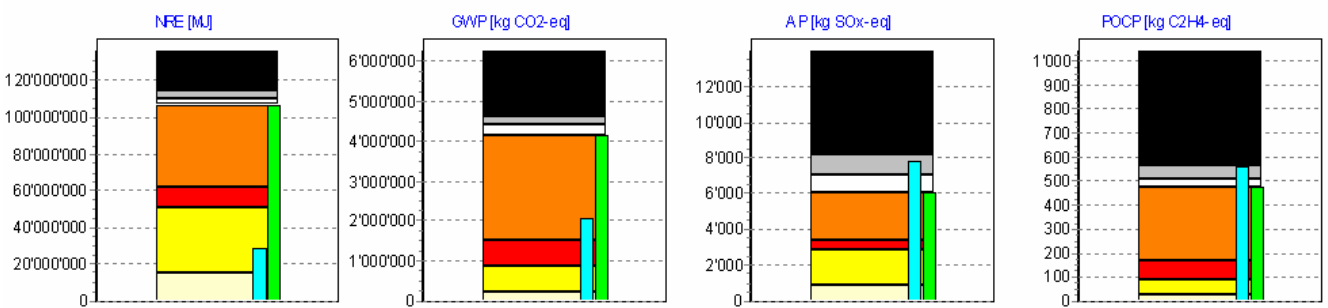

Fig. 9 Materials and energy impacts

We can see on Fig. 10 that the facades, floors, and internal main walls are the most important elements. They are responsible for around $70 \%$ of the building impacts. Inside these elements, we find a lot of reinforced concrete. The impacts of all the other elements put together account for only around $30 \%$ of the total impacts. If we take a look back at the materials-related impacts on Fig. 9, we can see why replacement impacts are so low. The concrete structure of the building, which has very high manufacturing impacts, is never replaced.

\begin{tabular}{|l|c|c|c|c|}
\hline \multicolumn{1}{|c|}{ Elements } & $\begin{array}{c}\text { NRE } \\
\text { [MJ] }\end{array}$ & $\begin{array}{c}\text { GWP } \\
\text { [kg CO2-eq] }\end{array}$ & $\begin{array}{c}\text { AP } \\
\text { [kg SOx-eq] }\end{array}$ & $\begin{array}{c}\text { POCP } \\
\text { [kg C2H4-eq] }\end{array}$ \\
\hline$\square$ Facades & $5^{\prime} 456^{\prime} 662.5$ & $352^{\prime} 543.8$ & $1^{\prime} 320.9$ & 113.0 \\
\hline$\square$ Floors & $7^{\prime} 198^{\prime} 681.1$ & $628^{\prime} 076.0$ & $2 ' 080.8$ & 144.4 \\
\hline$\square$ Roof & $1^{\prime} 469^{\prime} 470.9$ & $83^{\prime} 984.4$ & 375.7 & 22.1 \\
\hline$\square$ Terrace & $809^{\prime} 728.4$ & $49^{\prime} 327.5$ & 209.9 & 11.9 \\
\hline$\square$ Internal light walls & $1^{\prime} 330^{\prime} 744.9$ & $95^{\prime} 197.5$ & 293.2 & 21.7 \\
\hline$\square$ Internal main walls & $6^{\prime} 646^{\prime} 687.3$ & $498^{\prime} 774.6$ & $1 ' 846.7$ & 168.6 \\
\hline$\square$ Floor coatings & $2^{\prime} 108^{\prime} 516.9$ & $151^{\prime} 441.1$ & 557.4 & 16.4 \\
\hline$\square$ Windows type I & $620^{\prime} 908.6$ & $29^{\prime} 797.1$ & 229.9 & 9.5 \\
\hline$\square$ Windows type II & $1^{\prime} 069^{\prime} 671.0$ & $51^{\prime} 194.9$ & 363.2 & 16.7 \\
\hline$\square$ Windows type III & $252^{\prime} 042.9$ & $12^{\prime} 114.7$ & 97.9 & 3.8 \\
\hline$\square$ Windows type IV & $6^{\prime} 935.5$ & 333.6 & 2.8 & 0.1 \\
\hline$\square$ Sinks and toilets & 882.7 & 48.8 & 0.1 & 0.0 \\
\hline$\square$ First floor & $1^{\prime} 661^{\prime} 058.3$ & $133^{\prime} 341.8$ & 474.7 & 31.9 \\
\hline
\end{tabular}
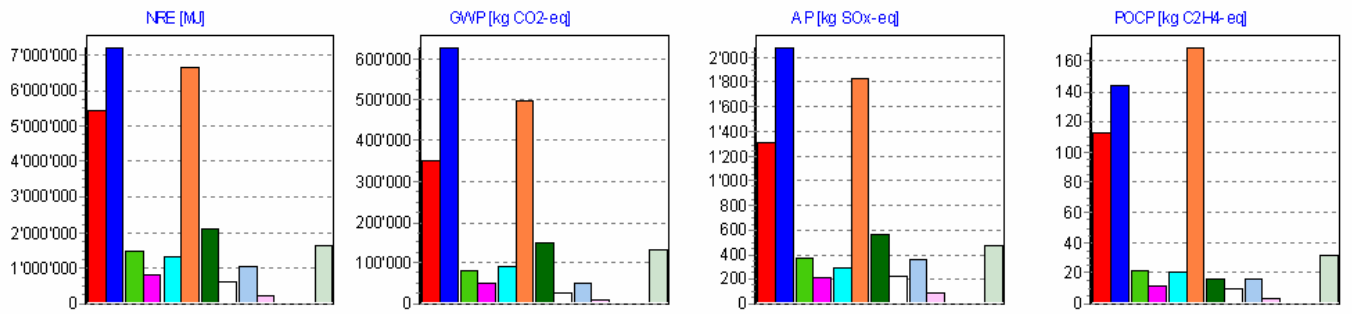

Fig. 10 Impacts of the building elements of the case study 


\begin{tabular}{|c|c|c|c|c|c|}
\hline Materials & $\begin{array}{l}\text { Weight } \\
{[\mathrm{kg}]}\end{array}$ & $\begin{array}{l}\text { NRE } \\
\text { [MJ] }\end{array}$ & $\begin{array}{c}\text { GWP } \\
\text { [kg CO2-eq] }\end{array}$ & $\begin{array}{c}\text { AP } \\
\text { [kg sox-eq] }\end{array}$ & $\begin{array}{c}\text { POCP } \\
{[\mathrm{kg} \mathrm{C} 2 \mathrm{H} 4-\mathrm{eq}]}\end{array}$ \\
\hline$\square$ Mineral cover coat & 347250.0 & $2^{\prime} 853^{\prime} 284.7$ & $165^{\prime} 391.1$ & 557.0 & 56.5 \\
\hline$\square$ Reinforced concrete for walls & 2598343.2 & $8^{\prime} 687^{\prime} 628.8$ & $671^{\prime} 582.0$ & $2 ' 529.6$ & 230.2 \\
\hline$\square$ Glass wool $\left(85 \mathrm{~kg} / \mathrm{m}^{3}\right)$ & 14280.0 & 1'316'651.8 & $45^{\prime} 486.3$ & 207.7 & 13.6 \\
\hline$\square$ Terra cotta bricks & 258720.0 & $9466^{\prime} 574.6$ & $78^{\prime} 097.2$ & 234.4 & 12.7 \\
\hline$\square$ Cement cast plaster floor & 770220.0 & $1^{\prime} 010^{\prime} 353.6$ & $148 ' 818.5$ & 333.5 & 11.0 \\
\hline$\square$ Polystyren expandable (EPS) & 3211.2 & $554^{\prime} 139.9$ & $18^{\prime} 286.5$ & 117.1 & 2.4 \\
\hline$\square$ Reinforced concrete for slab & 2741472.0 & $7^{\prime} 195^{\prime} 636.1$ & $610^{\prime} 044.6$ & $2^{\prime} 147.5$ & 166.4 \\
\hline$\square$ Waterproofing (Polymerbitum & 8040.0 & $878^{\prime} 689.3$ & $20^{\prime} 620.6$ & 146.3 & 5.2 \\
\hline$\square$ Carpet (polyamide) & 2676.0 & $1^{\prime} 6866^{\prime} 928.0$ & $125^{\prime} 009.6$ & 458.8 & 12.1 \\
\hline$\square$ PVC frame & 24777.7 & $1^{\prime} 407^{\prime} 824.6$ & $64^{\prime} 990.0$ & 404.7 & 22.1 \\
\hline
\end{tabular}
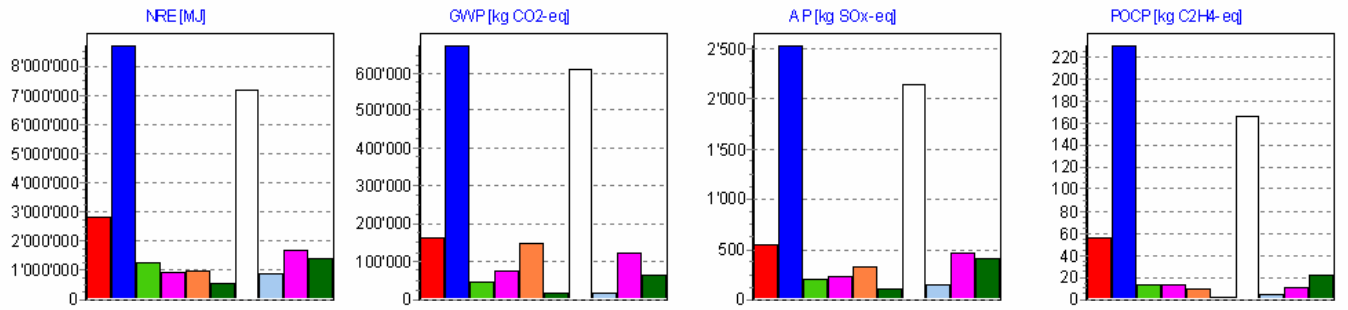

Fig. 11 Impacts of the building materials of the case study

Eco-Bat provides many different output format in order to help the designer. For instance, Fig. 11 shows the impacts of the 10 materials that generate the most impacts. They represent around $90 \%$ of the building total impacts. In this case study, the reinforced concrete from the walls and the floors accounts for a large part of those impacts for all four indicators. Other important materials include the cement cast plaster floor, mineral roughcast, ceramic tiling, and PVC window frames.

\section{Conclusion}

Eco-Bat is a user friendly tool developed to help designers to assess building's environmental impacts. It allows the description of a single element, in order to compare variants of a building element or the complete assessment of building, including construction materials and energy consumed during its life cycle.

Around 60 construction materials (minerals, metals, plastics, insulations, etc.) are available in Eco-Bat. The impacts data come from the Ecoinvent database and additional information, such as transport distances and elimination rates, has been obtained through practitioners.

To evaluate impacts related to energy consumption, the user must define the energy vector used as well as the consumption for each category (domestic hot water, heating, ventilation, lighting, cooling, and electrical equipment).

Detailed results analysis is available at different levels: the building, the elements, and the materials as well as the energy consumed.

Currently, Eco-Bat is used by architects, engineers, students, and practitioners. Its user-friendly, multilingual (English, French, and Italian) interface and its graphical representation allow a quick evaluation of the building impacts. Therefore, identifying materials, or energy consumers responsible of generating high impacts, is an easy task with Eco-Bat.

The next developments will be

- to include the Swiss methodology for eco-buildings,

- to add new indicators (EPS, Eco-indicator, etc.),

- to develop the concept for refurbishment,

- to add a German interface (soon).

Eco-Bat currently requires that the energy consumption of the building has already been calculated using another simulation tool. We are currently working with different partners to provide an integrated software which will allow simultaneously the assessment of the energy consumption, the environmental impacts, and the air quality evaluation, based on a single building description. This tool will be released before the end of 2008 .

\section{Acknowledgement}

We would like to thank Bureau d'Architectes et d'Ingénieurs B. Schlunegger for providing us with plans of the building they have designed. M. Frank Sapin from Architecture \& Acoustique SA, for helping us with this study and providing us with additional information. 


\section{References}

Citherlet S (2001). Towards the holistic assessment of building performance based on an integrated simulation approach. $\mathrm{PhD}$ Thesis. Federal Polytechnical School Lausanne, Switzerland.

Citherlet S, Defaux T (2007). Energy and environmental comparison of three variants of a family house during its whole life span.
Building and Environment, 42(2): 591 - 598.

EMPA - Ecoinvent Center, ECOINVENT 1.3, available at http://www.ecoinvent.org.

Hildbrand C, Citherlet S (2007). Environmental assessment with Eco-Bat of building equipment. Paper presented at CISBAT 2007, Lausanne. 